\title{
Publication Ethics-A Guide for Submitting Manuscripts to Pharmaceutical Research
}

\author{
Peter W. Swaan
}

Received: 2 June 2010 / Accepted: 3 June 2010 / Published online: 15 June 2010

(C) Springer Science+Business Media, LLC 2010

\section{INTRODUCTION}

In the current issue of Pharmaceutical Research, we publish an erratum that serves as a Notice of Duplicate Publication. In light of this, I wish to highlight the editors' standpoint on ethical violations during the publication process. Ethical transgressions can present themselves in many different shapes and forms, from the naïve duplication of data or verbatim copying of text, to outright deliberate plagiarism or data duplication, manipulation and falsification. These issues are becoming increasingly difficult to police because minor violations typically fall within a gray zone and are hard to detect unless a whistleblower alerts an editor to such issues. At Pharmaceutical Research, we take all allegations of ethical misconduct seriously and will pursue an investigation according to the guidelines of the Committee on Ethics in Publication (COPE; www.publicationethics.org). As stated on the COPE website, "COPE is a forum for publishers and editors of peer-reviewed journals to discuss issues related to the integrity of work submitted to or published in their journals. It supports and encourages editors to report, catalogue and instigate investigations into ethical problems in the publication process." Here, I will outline the different types of ethical issues we regularly observe at the editorial office and our current course of action once such transgressions have been detected.

P. W. Swaan $(\triangle)$

Department of Pharmaceutical Sciences

University of Maryland School of Pharmacy

20 Penn Street, HSFII Room 621

Baltimore, MD 21201-1075, USA

e-mail: pswaan@rx.umaryland.edu

\section{PLAGIARISM}

Plagiarism is the use of text from another author and the representation of it as one's own original work. However, we are seeing increasing occurrences of self-plagiarism, where an author liberally copies narrative from their own previous publications. Often enough, an author will claim that they are allowed to copy their own work; alas, when an article is published, its copyright is transferred to the publisher, and duplicating one's own work in successive manuscripts becomes a matter of copyright infringement.

How does the editorial office detect plagiarism? Upon submission, we currently check every manuscript with a software-based plagiarism detector, iThenticate ${ }^{\circledR}$ (www. ithenticate.com). This software compares each document to others in its custom database of published articles and various internet resources, thereby producing a similarity report. Any manuscript with a similarity $>20-25 \%$ will be subject to further inspection by the editorial office and the editor-in-chief. We will then determine whether similarity results from large blocks of text verbatim copied from other sources or whether there are many small pieces that contribute to an overall 'observed' similarity. Further, we will determine in what sections of the manuscript narrative appears to be plagiarized. It may be acceptable to find high similarity within the "Materials and Methods" section, but not in the "Introduction" or "Discussion" sections. In the end, the editorial office makes a judgment call that alerts the author to potential issues. Please note that verbatim copying of entire paragraphs (even in the "Methods" section) whether from other authors' or one's own prior work is never tolerated. These violations, if detected at the submission or review level, will result in manuscript rejection with a detailed explanation to the authors. As a service to authors, we will provide an iThenticate similarity 
report that outlines the copied text segments to aid in the revision process. Additionally, this tool may help authors to educate junior scientists in publication ethics. An unacceptably high degree of similarity $(>40-50 \%)$ will result in a warning letter to the corresponding author urging them to instruct themselves and their co-authors in ethical publication guidelines.

\section{DATA DUPLICATION}

The publication of identical data in any form, whether accidental or deliberate, is a serious breach of scientific ethics. Similar to plagiarism, we encounter various levels of data duplication, including altered representation of identical results. In the case of accidental duplication, the authors typically do not consider the duplication of supporting data (e.g., NMR or mass spectrometry data, physicochemical characterization of starting products/ monomers/polymers) as a breach of publication ethics. Nonetheless, these actions are considered data duplication and will result in the publication of an erratum or notice. Depending on the degree of data duplication, a full or partial retraction of the article may occur. As stated before, the process we follow at Pharmaceutical Research for dealing with these issues occurs via COPE guidelines. Typically, authors will be asked initially to clarify their actions and provide a written explanation. If the authors admit misconduct or their actions are deemed unethical (by a panel of editors), they may cooperate in authoring and publishing an erratum that outlines the degree of overlap between two already published articles. Linking of such notices to the original articles in Medline/PubMed will effectively alert the scientific community to irregularities in the publication process.

\section{CONCLUDING REMARKS}

Though the two sections above describe the journal's actions against the most commonly observed forms of ethical misconduct, additional offenses (e.g., disputed authorship, conflicts of interest) have been recognized and are outlined in the publisher's ethics policy (http:// www.springer.com/authors). The editorial office will deal with each occurrence on a case-by-case basis. In the end, both authors and reviewers can help identify ethical misconduct by alerting the editorial office to potential violations. As outlined in an excellent editorial by Grainger (1), reviewers share the responsibility to preserve quality control during the publication process. Using a vigilant and highly committed reviewer pool, our journal should be able to detect scientific misconduct prior to publication. Thus, I wish to impress to our readers that Pharmaceutical Research is committed to protecting the scientific publication process for both authors and reviewers by upholding the highest ethical standards.

\section{REFERENCE}

1. Grainger DW. Peer review as professional responsibility: a quality control system only as good as the participants. Biomaterials. 2007;28(34):5199-203. 